http://jmscr.igmpublication.org/home/ ISSN (e)-2347-176x ISSN (p) 2455-0450 crossref DOI: https://dx.doi.org/10.18535/jmscr/v10i2.24

Journal Of Medical Science And Clinical Research

\title{
Evaluation of depression status among migraine patients during COVID-19 pandemic situation in Dhaka: A Hospital Based Cross Sectional Study by using DASS 21 Scoring System
}

Authors

\section{Dr Md. Nazmuz Zaman Palash", Dr Kazi Mahbub Alam², Dr Syed Abdullah Sa-ad, Dr Khandakar Ashikur Zaman Imon ${ }^{4}$, Dr Md. Naim Ibna Bashar ${ }^{5}$, \\ Dr Farin Tamanna ${ }^{6}$ \\ ${ }^{1}$ Medical Officer, Neurology, Bangabandhu Sheikh Mujib Medical University Hospital (BSMMU)}

${ }^{2}$ Deputy Program Manager, Hospital Service Management, DGHS, Mohakhali, Dhaka-1212

${ }^{3}$ Asst. Registrar, Burn \& Plastic Surgery Dept. Shahid Sohrawardy Medical College, Dhaka

${ }^{4}$ Resident Medical Officer, Department of Paediatric respiratory medicine, Bangladesh Shishu Hospital \& Institute

${ }^{5}$ Junior consultant, Oculoplasty \& Ocular oncology, Ispahani Islamia Eye Institute \& Hospital, Farm

${ }^{6}$ Lecturer, Department of Pharmacology, Delta Medical College and Hospital, Dhaka

Corresponding Author

Dr Md. Nazmuz Zaman Palash

\begin{abstract}
This study was conducted to evaluate the depression status among migraine patients during COVID 19 pandemic situation in Dhaka. This was a cross sectional study which was taken at the outdoor of Bangabandhu Sheikh Mujib Medical University(BSMMU). This study was conducted in January to November 2021. Total 300 respondents with migraine and mental health problem were included in this study. DSS-21 scoring system was used as study tools in this study. Among 300 respondents 261 (87\%) were female and 39(13\%) were male. Among 261 female participants the prevalence of normal, mild, moderate, severe and extremely severe depression is reported respectively $12.7 \%, 38.7 \%, 27.3 \%, 4.3 \%$ and $4.0 \%$; among 39 male participants the prevalence of normal, mild, moderate, severe and extremely severe depression is reported respectively 2.0\%, 8.3\%, 2.3\%, 0.3\% and 0.0\%. No extremely severe depression male patient had found. The mean period for migraine suffering was reported 3.3982 years $\pm S D \pm 4.42$. The prevalence of depression for normal, mild, moderate, severe, and extremely severe is respectively $14.7 \%$, $47.0 \%, 29.7 \%, 4.7 \%$ and $4 \%$. The mean and $\pm S D$ for depression is $1.36 \pm 0.928$. The prevalence of Anxiety for normal, mild, moderate, severe, and extremely severe is respectively 7\%, 8\%, 53\%, $10.7 \%$ and $21.3 \%$. The mean and $\pm S D$ for anxiety is $2.31 \pm 1.107$. Therefore patients need to maintain proper lifestyle to protect from anxiety and depression to control migraine problem. There are 5 socio-demographic factors were associated with depression which were statistically significant (age $p=0.035$, education $p=0.000$, residence $p=0.000$, occupation $p=0.000$ and monthly income $p=0.000)$. Moreover type of migraine $(p=0.003)$, and anxiety $(p=0.000)$, were significantly associated with depression. Female are more prone to depression than male. Rich people have less depression than poor. Patients need to maintain proper lifestyle to protect from anxiety and depression to control migraine problem.
\end{abstract}

Keywords: Depression, Migraine Patients, DSS-21 Scoring System. 


\section{Introduction}

Depression is a common health issue globally. More than 264 million people are affected. Depression is distinct from mood movements that are transient and from everyday emotional reactions to problems of their personal lives. Depression can be extreme when lasting a long time and of mild to significant severity. Exposure to lead will cause the infected patient to suffer significantly and perform less optimally at work, school, and at home. According to American Psychiatric Association, Depression is a common psychiatric condition that adversely affects how you behave, the way you think and how you behave ${ }^{(1)}$.

Migraine is a common inherited multifactorial debilitating chronic signature neurovascular headache condition ${ }^{(2)}$. Although 12 percent of American adults suffer it, 2 predominantly female — in fact, it affects 3 times as many women as men $^{(3)(4)}$. The symptoms that follow migraine begin at an early stage and progress throughout the headache process, "suggesting that multiple neuronal systems function abnormally," structurally and functionally altering the brain (2). People with migraine have a higher prevalence of psychological diseases than other forms of headaches. Individuals with migraine are more vulnerable to being diagnosed with anxiety disorders, and those diagnosed with anxiety disorders are at a greater risk of migraine. Those suffering from depression have a more than 3-fold risk for developing migraines, but those with migraines that previously didn't have depression have a more than 3-fold risk for developing depression $^{(5)}$.

Many migraine patients suffer from symptoms of depression and anxiety. Migraine patients are between two to five times more likely to have these symptoms than patients without migraine. About $25 \%$ of patients with migraine have depression, and about $50 \%$ have anxiety. Some patients have symptoms of these disorders after living with migraine for years. Others develop them before migraine. At this time, scientists don't know the exact answer why all are so common. One of the brain chemicals involved in all these conditions is called serotonin. Hormone changes in women can also trigger both conditions. Symptoms of depression and anxiety are most common among people with chronic migraine, which is when headache attacks occur on 15 or more days a month. For people with fewer headaches, depression or anxiety puts them at risk for more headaches over time. Symptoms of depression and anxiety also impact other areas of health. Migraine patients with depression or anxiety have higher medical costs, are at increased risk for suicide, and have higher levels of disability than migraine patients without depression or anxiety. Also, and perhaps most importantly, headache treatments don't work as well when the depression or anxiety is not also being treated. Untreated patients are less likely to follow medicine or behavior treatment plans. They also show less response to headache medications, and are more likely to relapse. For these reasons, treating all these.

Patients reported that their migraines were more frequent and severe, and said they overused analgesics, according to the article published in The Journal of Headache and Pain ${ }^{(6)}$. Many also did not communicate with their neurologists. In addition, the authors from the IbnSina Hospital in Kuwait, determined that patients who were infected with COVID-19 reported a worsening of their headaches while they had the virus. In comparison to pre-pandemic period, approximately $60 \%$ of patients reported an increase in migraine frequency, $16 \%$ reported a decrease in frequency, and $10.3 \%$ transformed to chronic migraine.

Severe acute respiratory syndrome coronavirus 2 (SARS-CoV-2) emerged, and the disease was declared a pandemic in March 11, 2020 $0^{(7)}$. Since then, the healthcare systems worldwide have come under tremendous pressure as this ongoing public health epidemic has escalated. Neurologists are burdened with delivering quality care to many patients with chronic diseases, and at the same 
time, monitoring the spread of the CVID epidemic (8).

\section{Literature Review}

Migraine is widely considered one of the most crippling life-long neurological disorders, and people with migraine are disproportionately impacted by its consequences. Due to the high level of psychosocial stress, social isolation, disturbance of sleep and dietary patterns, as well as COVID-19-specific issues, some patients with migraine may lose their therapeutic response, particularly with cancellation of face-to-face visits and procedural treatments ${ }^{(9)}$. In an effort to respond to the situation headaches have been happening more often by introducing new methods such as phone calls or Internet-based applications. Too many of the countries were not capable of providing the same quality treatment as the other countries ${ }^{(10)}$. Migraines are rampant in Kuwait. A new population-based analysis of 15,523 subjects found that $30.1 \%$ of those surveyed were affected by episodic migraine, and $6.4 \%$ by chronic migraine (11)(12). We are not aware of the real-world effects of COVID-19 pandemic on patients with migraine to date.People with chronic migraine often experience depression or anxiety disorders. It's not uncommon for people with chronic migraine to struggle with lost productivity. They may also experience poor quality of life. Various study mentioned significant depression level among the migraine patients.

\section{Objectives}

\section{General Objective}

To evaluate the depression status among migraine patients during COVID 19 pandemic situation in Dhaka City.

\section{Specific Objective}

- To find out the prevalence of depression level, anxiety and migraine among the target group.

- To identify the correlation between depression and socio-demographic factors in pandemic situation.

- To examine the association between depression and clinical factor of migraine patients in pandemic situation.

\section{Conceptual Framework}

Independent Variables

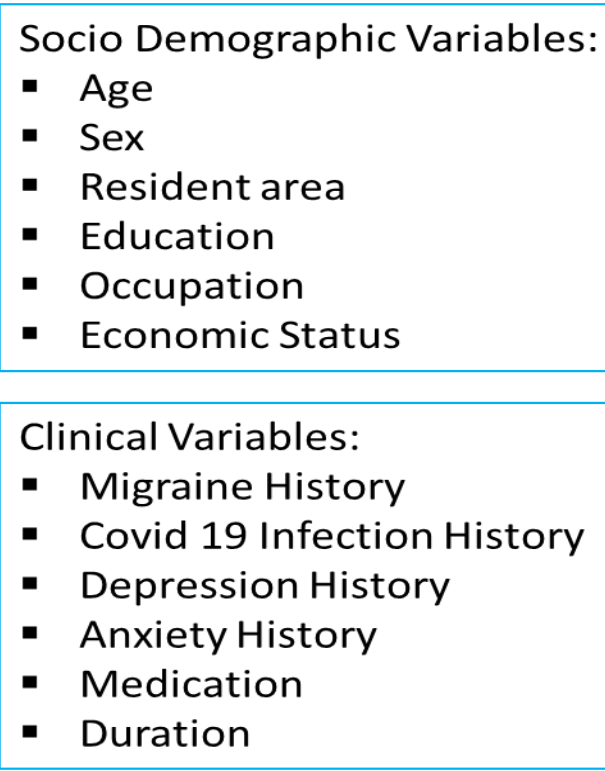

Dependent Variables

Depression status among migraine patients

Figure 1: Conceptual Framework 
Methodology

Study Design: This was a cross sectional study.

Study Location: This study was taken at the outdoor of Bangabandhu Sheikh Mujib Medical University (BSMMU).

Study Period: This study was conducted in the fall season of this year. Initially four-month time period, this study has been planned.

Study Population: Respondent from various economic status.

Study Sample: Simple random sampling was used for this study.

Sample calculation: To estimate proportion:

$$
\mathrm{N}=\left(\mathrm{z}^{2} \mathrm{pq}\right) / \mathrm{d}^{2}
$$

Here, $n=$ Number of sample

$\mathrm{z}=$ Level of significance / confidence level (at 5\% level, $\mathrm{z}=1.96$ )

$\mathrm{p}=$ Expected proportion of event or prevalence of the event.

$\mathrm{d}=$ Allowable error/precision in the estimates of 'p' (proportion)

The frequency of depression was observed in approximately three-quarters $(74.2 \%)$ of the migraine patients in the study of (Ahmed et. al. 2020) $)^{(13)}$.

$\mathrm{p}=.74 .2$

$\mathrm{q}=1-\mathrm{p}=0.258$

$$
\begin{gathered}
\mathrm{d}=.05(95 \% \mathrm{CI}) \\
\mathrm{N}=3.846 \text { X.74.2X.258/.0025 } \\
=295
\end{gathered}
$$

As per statistical formula we calculate 295 sample. Considering non-response missing data we have collect 300 samples for this study.

\section{Eligibility Criteria \\ Inclusion Criteria}

Must be migraine patient

\section{Exclusion Criteria}

$>$ Below 18 years old persons are outing range of this study.

$>$ Any student who is not psychologically fit to understand the questions

$>$ Any respondents who is not willing to participate

\section{Development of research instrument}

This was conducted by pre-tested questionnaire. The whole questionnaire was administrated by the researcher along with research assistants. The researcher was trained and advocates the assistants to collect data. Pre-tested data will be analyzed to see the accuracy of collected data.

\section{Plan for data collection}

One-month period was kept by planning for data collection. Researcher along with two research assistants was administrated the whole questionnaire.

\section{Plan for data analysis}

SPSS 23 and Microsoft Excel software used as principal software. STATA 24 used for some statistical analysis. JASP kept stand by for any kinds of complication.

\section{Data presentation and interpretation}

Data presented by compatible mixture of three basic methods. They are textual method, tabular method and graphical method. The demographic table and chart was introduced in Data presentation. The comparative analysis presented by a proper bar chart, pie chart or scatter plot. All tables of visual graphics representation were done by statistical software.

\section{Data quality management}

Data quality management was performed based on data integrity, completeness, validity, uniqueness, accuracy and consistency. Data quality management was started with finding out missing value, omit the repeated data, managed multiple data carefully. By this following data quality management was done.

\section{Ethical Issues}

- Study was performed with consent of respondent. There was no harm to human/animal in this study.

- It was ensured that their personal identity kept confidential and the data were used only for study purpose.

- Ethical clearance was taken from Bangladesh Bio-ethics Society. 


\section{JMSCR Vol||10||Issue||02||Page 127-135||February}

\section{Results}

\section{Socio-demographic status of the respondents}

Among 300 respondents 261 (87\%) were female and 39(13\%) were male. Among 261 female participants the prevalence of normal, mild, moderate, severe and extremely severe depression is reported respectively $12.7 \%, 38.7 \%, 27.3 \%$,
$4.3 \%$ and $4.0 \%$; among 39 male participants the prevalence of normal, mild, moderate, severe and extremely severe depression is reported respectively $2.0 \%, 8.3 \%, 2.3 \%, 0.3 \%$ and $0.0 \%$. No extremely severe depression male patient had found. The mean period for migraine suffering was reported 3.3982 years $\pm \mathrm{SD} \pm 4.42$.

\section{Table 1: Socio-demographic profile of the respondents}

\section{Prevalence of migraine, depression and anxiety:}

Among the 300 migraine patients the prevalence of depression for normal, mild, moderate, severe, and extremely severe is respectively $14.7 \%, 47.0 \%, 29.7 \%, 4.7 \%$ and $4 \%$. The mean and \pm SD for depression was $1.36 \pm 0.928$ (Figure 2). The prevalence of anxiety for normal, mild, moderate, severe, and extremely severe is respectively $7 \%, 8 \%, 53 \%, 10.7 \%$ and $21.3 \%$. The mean and \pm SD for anxiety is $2.31 \pm 1.107$ (Figure 3).

\begin{tabular}{|c|c|c|c|c|}
\hline Variables & Frequency & Percent \% & Mean & \pm SD \\
\hline \multicolumn{5}{|l|}{ Sex } \\
\hline Female & 261 & 87.0 & \multirow[t]{2}{*}{0.13} & \multirow[t]{2}{*}{0.337} \\
\hline Male & 39 & 13.0 & & \\
\hline \multicolumn{5}{|l|}{ Age } \\
\hline $18-24$ & 132 & 44.0 & \multirow[t]{6}{*}{0.97} & \multirow[t]{6}{*}{1.089} \\
\hline $25-30$ & 81 & 27.0 & & \\
\hline $31-40$ & 61 & 20.3 & & \\
\hline $41-50$ & 20 & 6.7 & & \\
\hline $51-60$ & 2 & 0.7 & & \\
\hline $60+$ & 4 & 1.3 & & \\
\hline \multicolumn{5}{|l|}{ Education } \\
\hline No Institutional Education & 19 & 6.3 & \multirow[t]{6}{*}{0.74} & \multirow[t]{6}{*}{0.439} \\
\hline Primary & 18 & 6.0 & & \\
\hline Secondary & 103 & 34.3 & & \\
\hline Higher secondary & 80 & 26.7 & & \\
\hline Graduate & 50 & 16.7 & & \\
\hline Post graduate & 30 & 10.0 & & \\
\hline \multicolumn{5}{|l|}{ Residence } \\
\hline Outside Dhaka & 78 & 26.0 & \multirow[t]{2}{*}{2.71} & \multirow[t]{2}{*}{1.282} \\
\hline Inside Dhaka & 222 & 74.0 & & \\
\hline \multicolumn{5}{|l|}{ Marital status } \\
\hline Unmarried & 73 & 24.3 & \multirow{2}{*}{$\begin{array}{l}0.76 \\
0.430\end{array}$} & \multirow[t]{2}{*}{0.430} \\
\hline Married & 227 & 75.7 & & \\
\hline \multicolumn{5}{|l|}{ Occupation } \\
\hline House wife & 138 & 46.0 & \multirow[t]{6}{*}{1.01} & \multirow[t]{6}{*}{1.227} \\
\hline Student & 75 & 25.0 & & \\
\hline Job & 58 & 19.3 & & \\
\hline Driver & 14 & 4.7 & & \\
\hline Retired & 6 & 2.0 & & \\
\hline Business & 9 & 3.0 & & \\
\hline \multicolumn{5}{|l|}{ Monthly income } \\
\hline$<10000$ & 125 & 41.7 & \multirow[t]{4}{*}{0.95} & \multirow[t]{4}{*}{0.938} \\
\hline $10000-20000$ & 78 & 26.0 & & \\
\hline $20000-30000$ & 83 & 27.7 & & \\
\hline $30000-50000$ & 14 & 4.7 & & \\
\hline
\end{tabular}




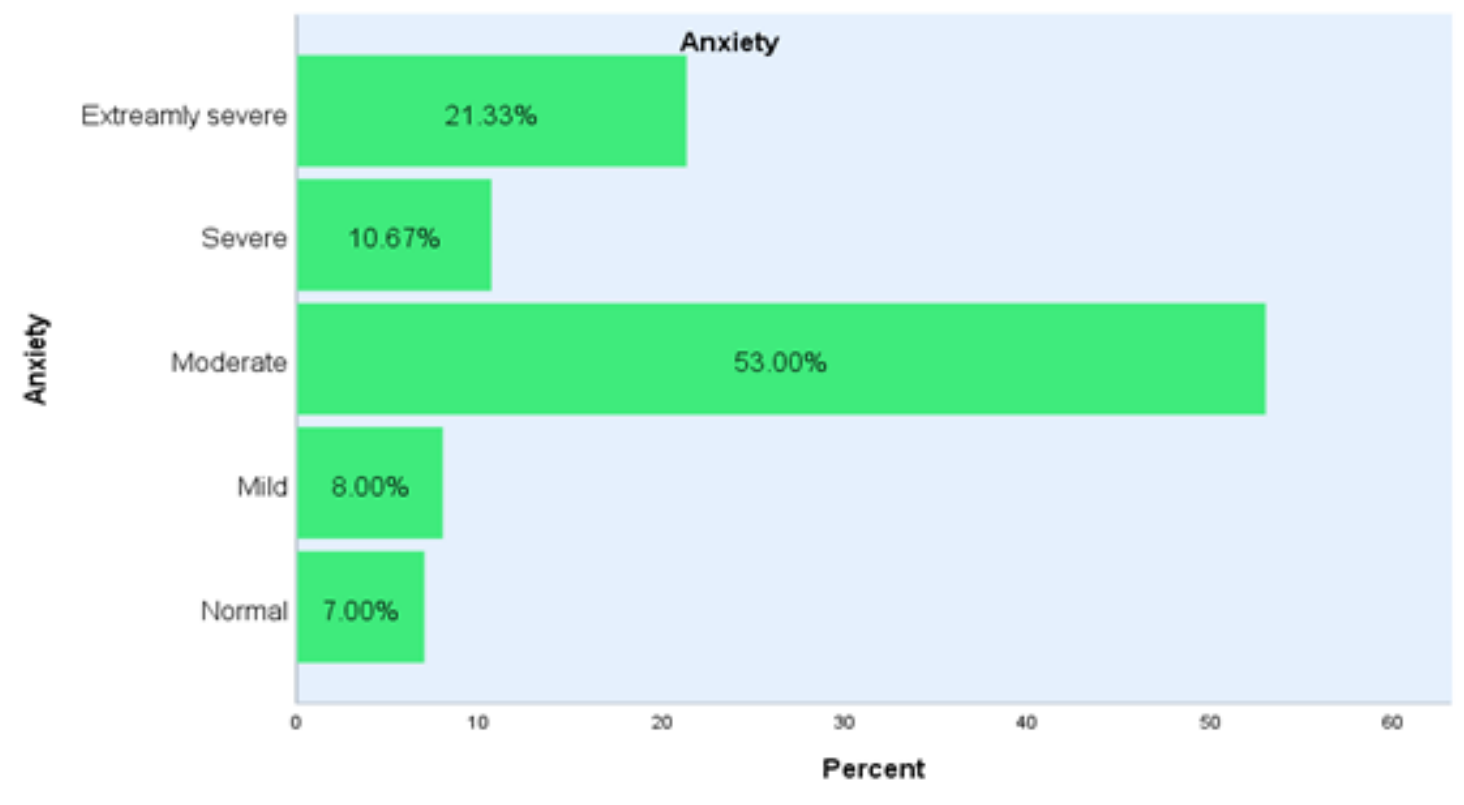

Figure 1: Prevalence level of anxiety

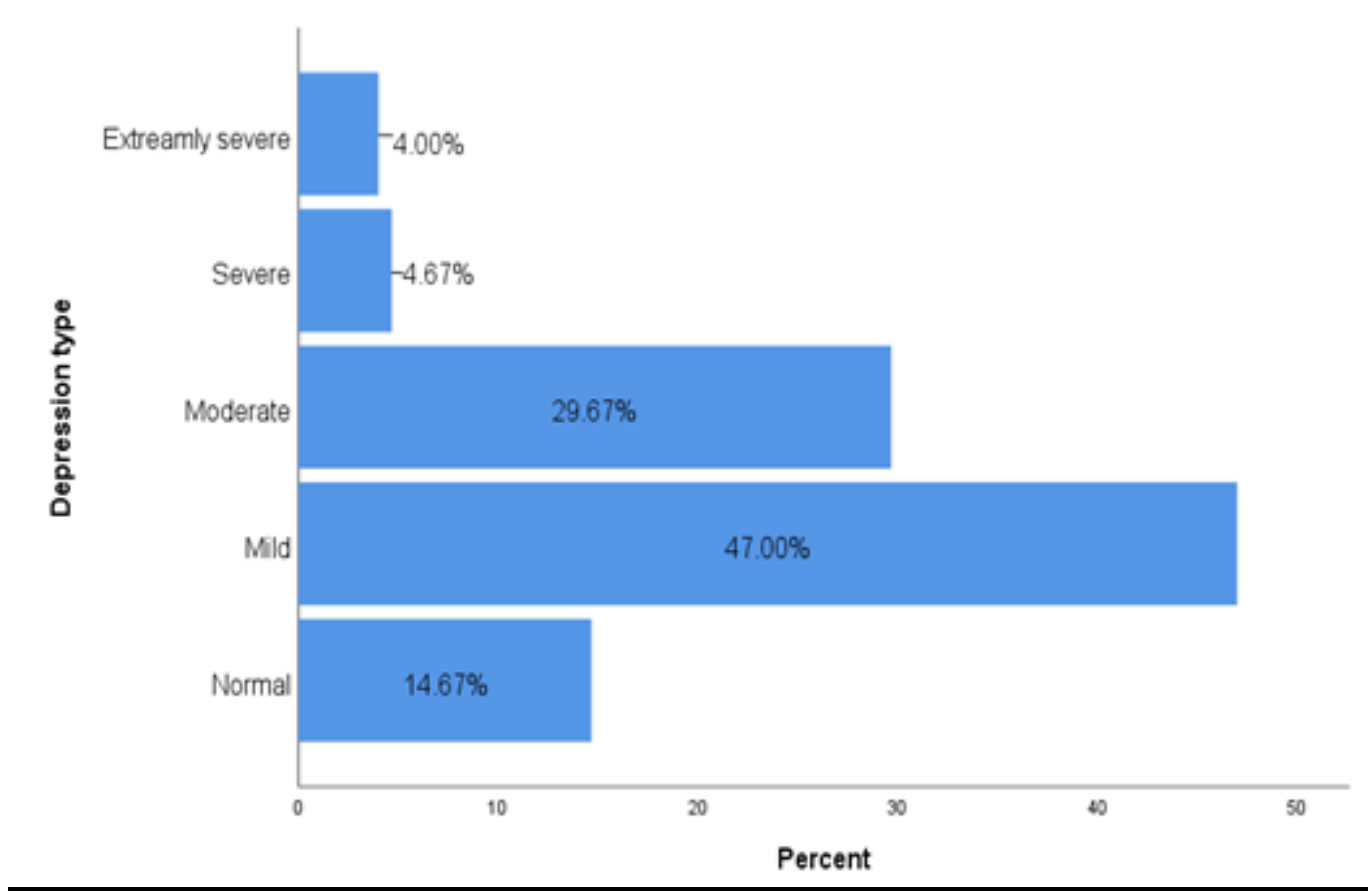

Figure 2: Prevalence of depression

\section{Depression and socio-demographic factors:}

Table 2 shows among 7 socio demographical factors, there 5 factors (age $\mathrm{p}=0.035$, education $\mathrm{p}=0.000$, residence $\mathrm{p}=0.000$, occupation $\mathrm{p}=0.000$ and monthly Income $\mathrm{p}=0.000$ ) are statistically significant associates with depression. Table 3 shows among 5 clinical variables, there 2 variables (type of migraine $\mathrm{p}=0.003$, and anxiety $\mathrm{p}=0.000)$ ) are statistically significant associates with depression. 
Table 2: Correlation between depression and socio-demographic factors $(\mathrm{N}=300)$

\begin{tabular}{|c|c|c|c|c|c|c|}
\hline \multirow[t]{2}{*}{ Description } & \multicolumn{5}{|c|}{ Depression type } & \multirow[t]{2}{*}{ P-Value } \\
\hline & Normal & Mild & Moderate & Severe & Extremely severe & \\
\hline \multicolumn{6}{|c|}{ Age } & \\
\hline \multirow[t]{2}{*}{$18-24$} & 13 & 58 & 47 & 9 & 5 & \multirow[t]{12}{*}{0.035} \\
\hline & $4.3 \%$ & $19.3 \%$ & $15.7 \%$ & $3.0 \%$ & $1.7 \%$ & \\
\hline \multirow[t]{2}{*}{$25-30$} & 12 & 39 & 23 & 2 & 5 & \\
\hline & $4.0 \%$ & $13.0 \%$ & $7.7 \%$ & $0.7 \%$ & $1.7 \%$ & \\
\hline \multirow[t]{2}{*}{$31-40$} & 15 & 24 & 18 & 3 & 1 & \\
\hline & $5.0 \%$ & $8.0 \%$ & $6.0 \%$ & $1.0 \%$ & $0.3 \%$ & \\
\hline \multirow[t]{2}{*}{$41-50$} & 3 & 16 & 1 & 0 & 0 & \\
\hline & $1.0 \%$ & $5.3 \%$ & $0.3 \%$ & $0.0 \%$ & $0.0 \%$ & \\
\hline \multirow[t]{2}{*}{$51-60$} & 1 & 1 & 0 & 0 & 0 & \\
\hline & $0.3 \%$ & $0.3 \%$ & $0.0 \%$ & $0.0 \%$ & $0.0 \%$ & \\
\hline \multirow[t]{2}{*}{$>60$} & 0 & 3 & 0 & 0 & 1 & \\
\hline & $0.0 \%$ & $1.0 \%$ & $0.0 \%$ & $0.0 \%$ & $0.3 \%$ & \\
\hline \multicolumn{7}{|c|}{ Sex } \\
\hline \multirow[t]{2}{*}{ Female } & 38 & 116 & 82 & 13 & 12 & 0.131 \\
\hline & $12.7 \%$ & $38.7 \%$ & $27.3 \%$ & $4.3 \%$ & $4.0 \%$ & \\
\hline Male & 6 & 25 & 7 & 1 & 0 & \\
\hline & $2.0 \%$ & $8.3 \%$ & $2.3 \%$ & $0.3 \%$ & $0.0 \%$ & \\
\hline Education & & & & & & \\
\hline No Institutional Education & 3 & 8 & 5 & 3 & 0 & \\
\hline & $1.0 \%$ & $2.7 \%$ & $1.7 \%$ & $1.0 \%$ & $0.0 \%$ & \\
\hline Primary & 2 & 2 & 8 & 1 & 5 & 0.000 \\
\hline & $0.7 \%$ & $0.7 \%$ & $2.7 \%$ & $0.3 \%$ & $1.7 \%$ & \\
\hline Secondary & 12 & 68 & 18 & 4 & 1 & \\
\hline & $4.0 \%$ & $22.7 \%$ & $6.0 \%$ & $1.3 \%$ & $0.3 \%$ & \\
\hline Higher secondary & 12 & 24 & 38 & 3 & 3 & \\
\hline & $4.0 \%$ & $8.0 \%$ & $12.7 \%$ & $1.0 \%$ & $1.0 \%$ & \\
\hline Graduate & 5 & 29 & 11 & 2 & 3 & \\
\hline & $1.7 \%$ & $9.7 \%$ & $3.7 \%$ & $0.7 \%$ & $1.0 \%$ & \\
\hline Post graduate & 10 & 10 & 9 & 1 & 0 & \\
\hline & $3.3 \%$ & $3.3 \%$ & $3.0 \%$ & $0.3 \%$ & $0.0 \%$ & \\
\hline Residence & & & & & & \\
\hline Outside Dhaka & 8 & 14 & 47 & 4 & 5 & 0.000 \\
\hline & $2.7 \%$ & $4.7 \%$ & $15.7 \%$ & $1.3 \%$ & $1.7 \%$ & \\
\hline Inside Dhaka & 36 & 127 & 42 & 10 & 7 & \\
\hline & $12.0 \%$ & $42.3 \%$ & $14.0 \%$ & $3.3 \%$ & $2.3 \%$ & \\
\hline Occupation & & & & & & \\
\hline House wife & 23 & 51 & 42 & 11 & 11 & 0.000 \\
\hline & $7.7 \%$ & $17.0 \%$ & $14.0 \%$ & $3.7 \%$ & $3.7 \%$ & \\
\hline Student & 7 & 33 & 32 & 2 & 1 & \\
\hline & $2.3 \%$ & $11.0 \%$ & $10.7 \%$ & $0.7 \%$ & $0.3 \%$ & \\
\hline Job & 10 & 33 & 14 & 1 & 0 & \\
\hline & $3.3 \%$ & $11.0 \%$ & $4.7 \%$ & $0.3 \%$ & $0.0 \%$ & \\
\hline Driver & 1 & 12 & 1 & 0 & 0 & \\
\hline & $0.3 \%$ & $4.0 \%$ & $0.3 \%$ & $0.0 \%$ & $0.0 \%$ & \\
\hline Retired & 3 & 3 & 0 & 0 & 0 & \\
\hline & $1.0 \%$ & $1.0 \%$ & $0.0 \%$ & $0.0 \%$ & $0.0 \%$ & \\
\hline Business & 0 & 9 & 0 & 0 & 0 & \\
\hline & $0.0 \%$ & $3.0 \%$ & $0.0 \%$ & $0.0 \%$ & $0.0 \%$ & \\
\hline Monthly Income & & & & & & \\
\hline$<10000$ & 19 & 12 & 69 & 13 & 12 & 0.000 \\
\hline & $6.3 \%$ & $4.0 \%$ & $23.0 \%$ & $4.3 \%$ & $4.0 \%$ & \\
\hline $10000-20000$ & 4 & 56 & 17 & 1 & 0 & \\
\hline & $1.3 \%$ & $18.7 \%$ & $5.7 \%$ & $0.3 \%$ & $0.0 \%$ & \\
\hline $20000-30000$ & 8 & 73 & 2 & 0 & 0 & \\
\hline & $2.7 \%$ & $24.3 \%$ & $0.7 \%$ & $0.0 \%$ & $0.0 \%$ & \\
\hline $30000-50000$ & 13 & 0 & 1 & 0 & 0 & \\
\hline & $4.3 \%$ & $0.0 \%$ & $0.3 \%$ & $0.0 \%$ & $0.0 \%$ & \\
\hline Marital Status & & & & & & \\
\hline Unmarried & 9 & 37 & 24 & 2 & 1 & 0.492 \\
\hline & $3.0 \%$ & $12.3 \%$ & $8.0 \%$ & $0.7 \%$ & $0.3 \%$ & \\
\hline Married & 35 & 104 & 65 & 12 & 11 & \\
\hline & $11.7 \%$ & $34.7 \%$ & $21.7 \%$ & $4.0 \%$ & $3.7 \%$ & \\
\hline
\end{tabular}


Table 3: Association between depression and clinical factor of migraine patients $(\mathrm{N}=300)$

\begin{tabular}{|c|c|c|c|c|c|c|}
\hline \multirow[t]{2}{*}{ Description } & \multicolumn{5}{|c|}{ Depression type } & \multirow[t]{2}{*}{ P-Value } \\
\hline & Normal & Mild & Moderate & Severe & $\begin{array}{c}\text { Extremely } \\
\text { severe }\end{array}$ & \\
\hline \multicolumn{7}{|c|}{ How long has migraine problem been going on? } \\
\hline \multirow{2}{*}{ Before Pandemic } & 36 & 107 & 65 & 9 & 8 & \multirow[t]{4}{*}{0.621} \\
\hline & $12.0 \%$ & $35.7 \%$ & $21.7 \%$ & $3.0 \%$ & $2.7 \%$ & \\
\hline \multirow[t]{2}{*}{ After Pandemic } & 8 & 34 & 24 & 5 & 4 & \\
\hline & $2.7 \%$ & $11.3 \%$ & $8.0 \%$ & $1.7 \%$ & $1.3 \%$ & \\
\hline \multicolumn{7}{|l|}{ Type of Migraine } \\
\hline \multirow[t]{2}{*}{ Mild } & 21 & 90 & 45 & 2 & 5 & \multirow[t]{4}{*}{0.003} \\
\hline & $7.0 \%$ & $30.0 \%$ & $15.0 \%$ & $0.7 \%$ & $1.7 \%$ & \\
\hline \multirow{2}{*}{ Chronic } & 23 & 51 & 44 & 12 & 7 & \\
\hline & $7.7 \%$ & $17.0 \%$ & $14.7 \%$ & $4.0 \%$ & $2.3 \%$ & \\
\hline \multicolumn{7}{|c|}{ Have you been affected by a COVID 19} \\
\hline \multirow[t]{2}{*}{ No } & 41 & 134 & 87 & 14 & 12 & \multirow[t]{4}{*}{0.550} \\
\hline & $13.7 \%$ & $44.7 \%$ & $29.0 \%$ & $4.7 \%$ & $4.0 \%$ & \\
\hline \multirow{2}{*}{ Yes } & 3 & 7 & 2 & 0 & 0 & \\
\hline & $1.0 \%$ & $2.3 \%$ & $0.7 \%$ & $0.0 \%$ & $0.0 \%$ & \\
\hline \multicolumn{7}{|l|}{ Anxiety } \\
\hline \multirow[t]{2}{*}{ Normal } & 20 & 0 & 1 & 0 & 0 & \multirow[t]{10}{*}{0.000} \\
\hline & $6.7 \%$ & $0.0 \%$ & $0.3 \%$ & $0.0 \%$ & $0.0 \%$ & \\
\hline \multirow[t]{2}{*}{ Mild } & 1 & 19 & 3 & 0 & 1 & \\
\hline & $0.3 \%$ & $6.3 \%$ & $1.0 \%$ & $0.0 \%$ & $0.3 \%$ & \\
\hline \multirow[t]{2}{*}{ Moderate } & 9 & 116 & 31 & 2 & 1 & \\
\hline & $3.0 \%$ & $38.7 \%$ & $10.3 \%$ & $0.7 \%$ & $0.3 \%$ & \\
\hline \multirow[t]{2}{*}{ Severe } & 2 & 3 & 27 & 0 & 0 & \\
\hline & $0.7 \%$ & $1.0 \%$ & $9.0 \%$ & $0.0 \%$ & $0.0 \%$ & \\
\hline \multirow[t]{2}{*}{ Extremely severe } & 12 & 3 & 27 & 12 & 10 & \\
\hline & $4.0 \%$ & $1.0 \%$ & $9.0 \%$ & $4.0 \%$ & $3.3 \%$ & \\
\hline
\end{tabular}

\section{Discussion}

In this study the prevalence of depression \& anxiety for normal, mild, moderate, severe, and extremely severe level is respectively $14.7 \%$, $47.0 \%, 29.7 \%, 4.7 \%$ and $4 \% ; 7 \%, 8 \%, 53 \%$, $10.7 \%$ and $21.3 \%$.A systemic review showed the prevalence of depression or depressive symptoms among medical students was $27.2 \%$ and that of suicidal ideation was $11.1 \%{ }^{(14)(13)}$.

Majority of the moderate depression (19.3\%) reported at age level of 18-24 years and 3.0\% severe depression was reported at the age group of 18-24 years. $27.3 \%$ moderate depression reported at female participants while man reported $2.3 \%$. No sever case have found at male while $4 \%$ extreme sever case have found at female participants.

$12.7 \%$ moderate depression survivor is higher secondary level educated. According to the working status among the participant $14.0 \%$ house wife were suffering with moderate depression. $4.3 \%$ severe depression survivor had monthly income below 10000 Taka.

Age $(\mathrm{p}=0.035)$, education $(\mathrm{p}=0.000)$, residence $(\mathrm{p}=0.000)$, occupation $(\mathrm{p}=0.000)$ and monthly Income $\mathrm{p}=(0.000)$ are statistically significant associates with depression. Type of migraine $(\mathrm{p}=0.003)$, and anxiety $(\mathrm{p}=0.000)$ are statistically significant associates with depression. A study found that parental factors with a sound evidence base indicating increased risk for both depression and anxiety include less warmth, more interparental conflict, over-involvement, and aversiveness; and for depression additionally ${ }^{(15)}$ (14) 


\section{Conclusion \& Recommendation}

Female are more prone to depression than male. Rich people have less depression than poor. Age, education, residence, occupation and monthly income are statistically significant associates with depression. Type of migraine and anxiety are statistically significant associates with depression. Patients need to maintain proper lifestyle to protect from anxiety and depression to control migraine problem. Furthermore study regarding depression and migraine problem is highly recommended.

\section{References}

1. American Psychiatric Association. What Is Depression? [Online].; 2020 [cited 2021 February 17. Available from: https://www.psychiatry.org/patientsfamilies/depression/what-is-depression.

2. Rami Burstein RNDB. Migraine: Multiple Processes, Complex Pathophysiology. The Journal of Neuroscience. 2015; 35(17): 6619-6629.

3. R. B. Lipton MEBMDFFMLRWFS. Migraine prevalence, disease burden, and the need for preventive therapy. Neurology. 2007; 68(5): 343-349.

4. K W Weitzel JMSKMSJVG. Genderspecific issues in the treatment of migraine. The journal of gender-specific medicine: JGSM: the official journal of the Partnership for Women's Health at Columbia. 2001; 4(1): 64-74.

5. P Torelli GLGCM. Psychiatric comorbidity and headache: clinical and therapeutical aspects. Neurological Science. 2006; Suppl 2: S73-S76.

6. Blank C. Study: Patients Report Worse Migraine Symptoms During COVID-19 Pandemic. [Online].; 2021 [cited 21 February 18. Available from: https://bit.ly/3s8udyv.
7. Carlos del Rio PNM. COVID-19-New Insights on a Rapidly Changing Epidemic. Jama. 2020; 323(14): 1339-1340.

8. Debashish Chowdhury DD. Managing migraine in the times of COVID-19 pandemic. Annals of India Academy of Neurology. 2020; 23(7): 33-39.

9. Christina L. Szperka MD MJAMRBMBCKMMMTMMMRBHSMR ESMP. Migraine Care in the Era of COVID- 19: Clinical Pearls and Plea to Insurers. Headache. 2020; 60(5): 833-842.

10. Matias-Guiu pMGJPEELVIGMAGSJA. The management of neurological care in times of the Covid-19 pandemic. Neurology. 2020; 35(4): 233-237.

11. Jasem Yousef Al-Hashel SFA\&RA. Burden of migraine in a Kuwaiti population: a door-to-door survey. The Journal of Headache and Pain. 2017; 105(18): 1-6.

12. Yohannes W. Woldeamanuel RPC. Migraine affects 1 in 10 people worldwide featuring recent rise: A systematic review and meta-analysis of community-based studies involving 6 million participants. Journal of the Neurological Sciences. 2016; 372: 307-315.

13. Rotenstein LSea. Prevalence of Depression, Depressive Symptoms, and Suicidal Ideation Among Medical Students: A Systematic Review and MetaAnalysis. JAMA. 2016; 316,21: 22142236.

14. Yap MBHea. Parental factors associated with depression and anxiety in young people: a systematic review and metaanalysis. Journal of affective disorders. 2014; 156: 8-23. 